\title{
IDENTIDADE MODERNA - PERSPECTIVAS DO COMUNITARISMO
}

\section{Tatyana Scheila Friedrich}

RESUMO: O comunitarismo surge no contexto da dominação hegemônica norte-americana no século $X X$, com o objetivo de proceder, a partir da idéia de eticidade concreta, à reconstrução histórica da noção de "tradição cultural". Aparece em contraposição ao liberalismo da filosofia política, do racionalismo universalista, da filosofia analítica, do emotivismo ético e, por fim, como crítica da modernidade. Levando em consideração diversos "momentos materiais ou de conteúdo", as diferentes linhas do comunitarismo concentram na idéia de tradições autônomas, com pressupostos próprios, não admitindo debates entre si. Enrique Dussel elenca os três principais autores dessa corrente filosófica: Alasdair Maclntyre, com análise a partir da reinterpretação do ethos histórico cultural de Aristóteles e considerando o momento material das "virtudes"; Charles Taylor, a partir da localização da eticidade de Hegel e focando nos momentos "valores e autenticidade de cada identidade"; e Michael Walzer, a partir dos princípios materiais inerentes às diferentes esferas institucionais para tratar da questão da justiça, e da tolerância. José Eduardo Faria, ao prefaciar Gisele Cittadino, inclui ainda o autor Michael Sandel e separa os comunitaristas dos libertários, como Robert Nozick e Friedrich Hayek; dos liberais contratualistas, como John Rawls e Ronald Dworkin e dos críticos-deliberativos, como Jürgen Habermas. $O$ comunitarismo está contextualizado no momento material da ética, que se dedica à verdade prática. No entanto, suas premissas têm alcance no quinto momento, o da validade antihegemônica da comunidade das vítimas. A discussão sobre a generalidade dos valores, a valorização das tradições e particularidades, a limitação das coisas a cada cultura está presente na crítica ao consenso exacerbado, na percepção da negação existente e nas iniciativas de novas frentes de libertação do sujeito. Os novos sujeitos de direito que surgem, diante da existência da negatividade e da necessidade de afirmação, trazem consigo suas tradições. Os seres são comunitários e seus momentos de reação refletem isso. A construção da identidade moderna, da noção de si mesmo, decorre da tradição. A modernidade não começa somente no período moderno, muito antes dessa fase já havia tradições. As fontes do eu (self), ou a identidade, estão nas tradições. Os conceitos universais, na verdade, não têm tal amplitude universalista porque partem sempre de uma tradição. Noções da relação interno-externo são levadas em consideração, conforme a opinião da cada autor comunitarista, expostos na versão integração do presente trabalho.

PALAVRAS-CHAVE: Filosofia, Comunitarismo, Universalismo, Filosofia da Libertação, Tradição 


\section{COMUNITARISMO}

O comunitarismo surge no contexto da dominação hegemônica norteamericana no século XX, com o objetivo de proceder, a partir da idéia de eticidade concreta, à reconstrução histórica da noção de "tradição cultural". Aparece em contraposição ao liberalismo da filosofia política, do racionalismo universalista, da filosofia analítica, do emotivismo ético e, por fim, como crítica da modernidade.

Levando em consideração diversos "momentos materiais ou de conteúdo", as diferentes linhas do comunitarismo concentram na idéia de tradições autônomas, com pressupostos próprios, não admitindo debates entre si.

Enrique Dussel elenca os três principais autores dessa corrente filosófica: Alasdair Maclntyre, com análise a partir da reinterpretação do ethos histórico cultural de Aristóteles e considerando o momento material das "virtudes"; Charles Taylor, a partir da localização da eticidade de Hegel e focando nos momentos "valores e autenticidade de cada identidade"; e Michael Walzer, a partir dos princípios materiais inerentes às diferentes esferas institucionais para tratar da questão da justiça, e da tolerância.

José Eduardo Faria, ao prefaciar Gisele Cittadino, inclui ainda o autor Michael Sandel e separa os comunitaristas dos libertários, como Robert Nozick e Friedrich Hayek; dos liberais contratualistas, como John Rawls e Ronald Dworkin e dos críticos-deliberativos, como Jürgen Habermas. E sobre os comunitaristas, resume a posição da autora ao afirmar que eles "recuperaram a tradição aristotélica ao (a) por em xeque a pressuposição de um sujeito universal e não situado historicamente, (b) enfatizar a multiplicidade de identidades sociais e culturas étnicas presentes na sociedade contemporânea e (c) conceber a justiça como a virtude na aplicação de regras conforme as especificidades de cada meio ou ambiente social, criticando os liberais por não serem capazes de lidar com as situações intersubjetivas e de ver os diálogos apenas como uma 'sucessão alternada de monólogos' ". 1

A noção de pluralismo é essencial para a compreensão do que seja o comunitarismo. Cittadino explica que o pluralismo tem dois significados diferentes e apenas um deles é usado pelos comunitaristas:

1 FARIA. José Eduardo in Prefácio à obra Pluralismo, Direito e Justiça Distributiva. Elementos da Filosofia Constitucional Contemporânea. Rio de Janeiro: Editora Lúmen Juris, 2004. p. xviii e xix. 
(...) o Pluralismo, entretanto, possui, pelo menos, duas significações distintas: ou o utilizamos para descrever a diversidade de concepções individuais acerca da vida digna ou para assinalar a multiplicidade de identidades sociais, específicas culturalmente e únicas do ponto de vista histórico.

No âmbito da filosofia política contemporânea, os representantes do pensamento liberal - John Rawls, Ronald Dworkin e Charles Larmore, dentre outros - adotam o primeiro significado do pluralismo e descrevem as democracias modernas como sociedades onde coexistem distintas concepções individuais acerca do bem. Quanto à segunda significação do pluralismo, são os representantes do pensamento comunitário, Charles Taylor e Michael Walzer, dentre outros, que a utilizam para salientar a multiplicidade de identidades sociais e de culturas étnicas e religiosas que estão presentes nas sociedades contemporâneas. ${ }^{2}$

O comunitarismo está contextualizado no momento material da ética, que se dedica à verdade prática. No entanto, suas premissas têm alcance no quinto momento, o da validade anti-hegemônica da comunidade das vítimas. A discussão sobre a generalidade dos valores, a valorização das tradições e particularidades, a limitação das coisas a cada cultura está presente na crítica ao consenso exacerbado, na percepção da negação existente e nas iniciativas de novas frentes de libertação do sujeito. Os novos sujeitos de direito que surgem, diante da existência da negatividade e da necessidade de afirmação, trazem consigo suas tradições. Os seres são comunitários e seus momentos de reação refletem isso.

A construção da identidade moderna, da noção de si mesmo, como se verificará, decorre da tradição. A modernidade não começa somente no período moderno, muito antes dessa fase já havia tradições. As fontes do eu (self), ou a identidade, estão nas tradições. Os conceitos universais, na verdade, não têm tal amplitude universalista porque partem sempre de uma tradição. Noções da relação interno-externo são levadas em consideração, conforme a opinião da cada autor comunitarista, expostos na seqüência.

2 CITTADINO, Gisele. Pluralismo, Direito e Justiça Distributiva. Elementos da Filosofia Constitucional Contemporânea. Rio de Janeiro: Editora Lúmen Juris, 2004. p. 1 e 2. 


\section{Alasdair Macintyre}

Macintyre propõe-se a definir a racionalidade tendo em vista que ela pode retornar às ações morais e sociais a partir da revisão da tradição aristotélica, bem como explicitar as crenças sobre a racionalidade prática presentes nas visões da justiça, estabelecendo uma conexão entre justiça e lei. "Prometi um livro no qual tentaria dizer o que faz com que seja racional agir de um modo e não de outro, e o que faz com que seja racional propôr e defender uma concepção da racionalidade prática e não outra. Eis aqui o livro. ${ }^{3}$

Atualmente, o mundo está inserido numa cultura em que não se chega, quanto ao tema da natureza da justiça e da racionalidade prática, a conclusões comuns e racionalmente justificáveis, além de existirem grupos sociais em oposição que se utilizam de conjuntos de convicções rivais e conflitantes não baseadas na justificação racional. As questões relativas à justiça e racionalidade prática não são abordadas como tema de pesquisa racional, mas no domínio público, a partir de afirmações e contra-afirmações de conjuntos de premissas alternativas e incompatíveis. Isso se deu em virtude do lluminismo que propugnou pela razão tomando o lugar da autoridade e da tradição e estabeleceu que a justificação racional deveria partir de "princípios inegáveis a qualquer pessoa racional e, portanto, independentes de todas as particularidades sociais e culturais que os pensadores do lluminismo consideravam mera roupagem acidental da razão em lugares e épocas particulares". Ocorre, porém que, na prática, os próprios iluministas não chegaram a um consenso sobre esses princípios inerentes, gerando uma série de divergências.

Conseqüentemente, o legado do lluminismo é a provisão de um ideal de justificação racional que se mostrou impossível atingir. É daí principalmente que decorre a inabilidade, dentro de nossa cultura, de unir convicção e justificação racional. Dentro do tipo de filosofia acadêmica, herdeiro das filosofias do lluminismo, a pesquisa sobre a natureza da justificação racional tem continuado com refinamento e divergência crescentes. Na vida cultural, política, moral e religiosa a convicção pós-iluminista adquiriu efetivamente uma vida própria, independente da pesquisa racional. ${ }^{4}$ prefácio.

${ }^{3}$ MACINTYRE, Alasdair. Justiça de quem? Qual racionalidade? 2 ed. São Paulo: Loyola, 2001. p. 7

${ }^{4}$ MACINTYRE, p. 17. 
Segundo o autor, é preciso, então, buscar um tipo de compreensão que o lluminismo excluiu, mas que seja capaz de oferecer os recursos conceituais e teóricos necessários para resgatar a convicção em temas como justiça e justificação racional. Trata-se da pesquisa racional constituída e constitutiva da tradição - esta que havia sido descartada pelo lluminismo por ser considerada como a antítese da pesquisa racional.

O que pretendo mostrar é que aquilo para o que o lluminismo nos cegou, e que agora precisamos recuperar, é uma concepção da pesquisa racional incorporada numa tradição; uma concepção de acordo com a qual os próprios padrões da justificação racional avultem e façam parte de uma história na qual eles sejam exigidos pelo modo como transcendem as limitações e fornecem soluções para as insuficiências de seus predecessores, dentro da história dessa mesma tradição. ${ }^{5}$

No entanto, para que haja uma boa compreensão do conceito de um tipo de pesquisa racional que seja inseparável da tradição social e intelectual na qual está incorporado, será necessário observar quatro aspectos fundamentais: o conceito de justificação racional é histórico, contextual, com diversidade de tradições e elucidado a partir de exemplificações, "algo que considero verdadeiro em relação a todos os conceitos, mas que é mais importante não negligenciar em alguns casos do que em outros". 6

No que tange essa exemplificação, Macintyre lança mão de quatro exemplificações que apresentam padrões de desenvolvimento muito diferentes mas que são essenciais, haja vista que cada uma delas é parte do substrato histórico de nossa cultura; traz consigo um tipo distinto de visão da justiça e da racionalidade prática; entrou em relação de antagonismo ou de aliança ou mesmo de síntese, ou de ambas sucessivamente, com pelo menos uma das outras ${ }^{7}$ :

1) A visão de Aristóteles (Ética a Nicômaco e Política) sobre justiça e racionalidade prática emerge do contexto cultural dos conflitos da pólis antiga.

Espero que a argumentação precedente tenha deixado bastante claro que não se pode ser justo, segundo Aristóteles, sem a capacidade de raciocínio prático (...) Mas uma vez que o

\footnotetext{
${ }^{5}$ MACINTYRE, p.18

${ }^{6}$ MACINTYRE, p. 21

${ }^{7}$ Idem.
} 
raciocínio prático, tal como Aristóteles o compreende, implica a capacidade de relacionar as premissas relevantes com relação a bens e virtudes a situações particulares, e uma vez que essa capacidade é inseparável e, na verdade, uma parte das virtudes, inclusive a justiça, é também verdade que ninguém pode ser praticamente racional sem ser justo. $E$, por razões que são essencialmente as mesmas, chegamos à conclusão de que não se pode ser justo ou racional de modo prático sem pertencer a alguma pólis particular. Uma idéia conflitante com visões caracteristicamente modernas da racionalidade é a de que a racionalidade de alguém não é meramente sustentada, mas parcialmente constituída por sua inserção e integração numa instituição social de algum tipo. ${ }^{8}$

2) Posteriormente essa visão é desenvolvida por São Tomás de Aquino (Suma Teológica) de uma maneira que vai além da pólis, até um tipo mais complexo de comunidade em que elementos seculares e religiosos integram-se, desenvolvendo relações ora de síntese ora de antagonismo com o pensamento de Aristóteles e introduzindo-lhe elementos agostinianos.

Contra os aristotélicos contemporâneos, São Tomás estava determinado a mostrar que, tanto naquilo que aceitou de Aristóteles, como no que retificou ou dispensou, chegou genuinamente a um acordo com as argumentações de Aristóteles. Da mesma forma, contra os agostinianos contemporâneos, estava comprometido com um tratamento dos textos patrísticos e agostinianos que reconhecia o que thes era devido. E, mais fundamentalmente, não podia aceitar nada de nenhum deles que fosse inconciliável com as Escrituras.

Consideremos o tratamento dado por São Tomás à injustiça. Ao concordar com Aristóteles que cada virtude é exercida de acordo com uma média (S. T. la-llae, 64,2) ele, entretanto, não chega ao pondo de compreender a justiça como uma virtude intermediária entre dois vícios, como Aristóteles. A injustiça é, por assim dizer, um vício com um único propósito, o de estar deliberadamente disposto a opor-se àquilo que é exigido pela justiça (S. T. la-Ilae, 59). Pode-se opôr à justiça atribuindo a alguém mais ou menos do que lhe é devido e nisso o padrão da média pode ser discernido. Mas o modo particular no qual a justiça é desconsiderada é menos importante do que a vontade de fazê-lo. E quanto a isso São Tomas segue Agostinho e não Aristóteles. ${ }^{9}$

3) Na Escócia do século XVII, o cristianismo de Santo Agostinho, então numa versão calvinista, e a filosofia de Aristóteles, então em versão renascentista,

${ }^{8}$ MACINTYRE, p. 137. 
encontraram-se. Hutcheson (livros: Institutio e Um Sistema da Filosofia Moral) realizou reformulações de posições mais antigas, com base no caminho das idéias, tendo em vista a dificuldade dos aristotélicos escoceses em responder às dúvidas epistemológicas sobre os primeiros princípios e sobre a simbiose do agostinismo calvinista com o aristotelismo.

As verdades morais que Hutcheson tinha herdado, em parte do aristotelismo escolástico, em parte do calvinismo, expressavam uma visão do conteúdo da justiça especificável somente por princípios cuja verdade e cuja demanda por nossa adesão independem do interesse ou vantagem de qualquer pessoa ou grupo de pessoas particulares. Para perseguir a justiça, a pessoa deve ser capaz de transcender quanto a leve a buscar seu interesse próprio e o que quer que a leve a consultar o interesse de outros grupos, independentemente do tamanho desses grupos. Fazer justiça significa distribuir, de acordo com o merecimento, não segundo os interesses: a justiça concebida dessa forma não pode aparecer como servindo ao interesse de alguém ou de todos, seja numa visão hobbesiana, seja numa visão derivada da generosa concepção da natureza humana proposta por Shaftesbury. ${ }^{10}$

Ainda na Escócia, a partir do pensamento de Hume (obra: Tratado da Natureza Humana), a tentativa de aproximação das duas filosofias vai sofrer uma subversão, mas ainda expressando um tipo particular de sociedade anglicana, baseada na idéia de reciprocidade da paixão e interesse.

Neste caso, ao contrário, temos concepções do raciocínio prático e da justiça que são propostas em esquemas conceituais muito diferentes, que empregam modos de caracterização e argumentação totalmente diferentes, e que, ademais, são claramente incompatíveis. O que Hume considera justo seria, na visão de Aristóteles, freqüentemente, injusto; a noção de merecimento ocupa, na visão de Aristóteles, um lugar que lhe é negado na visão de Hume; na visão de Aristóteles, a razão, concebida de um certo modo, é capaz de governar e educar as paixões, ao passo que, na visão de Hume, a razão, concebida de um modo bastante diferente, só pode se submeter a elas. Há, certamente, alternativas coerentes para a opção

${ }^{9}$ MACINTYRE, p. 222 e 223.

${ }^{10}$ MACINTYRE, p. 299. 
entre ser aristotélico ou humiano, mas qualquer aristotélico está, automaticamente, comprometido com a negação das asserções fundamentais de Hume, e vice-versa. ${ }^{11}$

4) Macintyre estabelece a necessidade de escrever a história narrativa de uma quarta tradição: o liberalismo. Este surge como mais uma tradição, ainda que essa fosse sua aversão conceitual.

Entretanto, é da maior importância ter em mente que o projeto de fundar um tipo de ordem social, no qual os indivíduos possam emancipar-se da contingência e a particularidade da tradição, através do recurso a normas genuinamente universais e independentes da tradição, não foi e não é apenas, nem principalmente, um projeto de filósofos. Ele foi e é o projeto da sociedade liberal moderna e individualista, e as razões mais convincentes que temos para acreditar que a esperança de universalidade racional independente da tradição é uma ilusão, derivam da história desse projeto. Pois, no curso dessa história, o liberalismo que começou como um apelo a supostos princípios de racionalidade compartilhada, contra o que se considerava a tirania da tradição, foi transformado em tradição cujas continuidades são parcialmente definidas pela interminabilidade do debate de tais princípios. Essa interminabilidade que, do ponto de vista do liberalismo nascente, era um grave erro a ser remediado o mais rápido possível, tornou-se, pelo menos aos olhos de alguns liberais, um tipo de virtude. ${ }^{12}$

Outras tradições são reconhecidas pelo autor, tais como as tradições judaicas, islâmicas, outras pós-bíblicas, indianas, chinesas. Essas quatro exemplificações, no entanto, demonstram a confirmação da racionalidade de uma tradição aristotélica e são suficientes para organizar a idéia da pesquisa das tradições em torno das seguintes características:

- O resgate da noção de tradição é uma reação à proposta do lluminismo de fornecer padrões de julgamento racional impessoais e neutros, que independem da tradição e que fazem com que nenhum conjunto de crenças proposto seja justificável. É também a contestação da visão iluminista particular da verdade e da racionalidade, através da qual a verdade é garantida pelo uso do método racional e dos princípios inegáveis por qualquer ser plenamente reflexivo e racional.

\footnotetext{
${ }^{11}$ MACINTYRE, p. 354.

${ }^{12}$ MACINTYRE, p. 361.
} 
- Cada tradição só deve ser apropriada através da relação com sua história contingente particular, o que não impede que as histórias das tradições se estendam a ambientes diferentes e até hostis.

- Cada tradição reflete o modo de vida social e moral de que é parte integrante, diferenciando-se entre si não só em relação aos temas da justiça e racionalidade prática, que são atingidos por processos diferentes, mas também nas concepções de virtudes, do eu, das cosmologias metafísicas, de seu histórico. Há um intenso diálogo dentro de uma mesma tradição mas só assim é que se pode chegar às concepções da racionalidade prática e da justiça - cada tradição fornece os termos, as justificativas, os conceitos e os padrões pelos quais se define, em cada estágio de seu desenvolvimento. O que não existe é um conjunto de padrões comuns ou independentes de justificação racional que pode decidir as questões entre tradições discordantes. Disputas entre estas não são passíveis de ser decididas racionalmente. Mas isso não implica que, o que se diz numa tradição, não possa ser ouvido por outra.

- O debate da natureza da pesquisa da tradição é feito para que se possa, à medida do possível, chegar a uma concepção verdadeira da justiça e da racionalidade, as quais aparecem como aspectos ligados a uma visão geral mais ampla e articulada da vida humana e de seu lugar na natureza, mas que também são tradições expressas em tipos particulares de relações sociais.

- Diante de perguntas ligadas à problemática da justiça e racionalidade prática, que admitem concepções sistemática rivais das tradições conflitantes entre si (guerra, discriminação positiva, etc.), a resposta vai depender de quem a pessoa é e como ela se compreende. São variantes, além da situação histórica, social e cultural das pessoas que trazem esses problemas, também a história das crenças e atitudes de cada pessoa particular que enfrenta tais problemas - possibilitando inclusive um ocasião para auto-reconhecimento e autoconhecimento.

- A adesão, enquanto agente racional, a uma tradição particular de pesquisa, exige o reconhecimento de estar ligado a um conjunto de crenças que carece de justificação e de estar desprovido daquilo que uma 
tradição proporciona. Ela exige o encontro com uma língua-em-uso que torne o agente capaz de estabelecer um diálogo com alguma (ou mais de uma) tradição de pesquisa, reconhecendo algo além das expressões de vontade e preferência.

Macintyre argumenta que sua obra conclui-se, demonstrando o "onde" e "como" começar a discussão contemporânea substancial sobre as tradições particulares de pesquisa, em relação à justiça e racionalidade, instigando-nos com uma série de questionamentos:

Nós, quem quer que sejamos, só podemos começar a pesquisa a partir da perspectiva oferecida por nossa relação com um passado social e intelectual, específico, através do qual nos afiliamos a uma tradição particular de pesquisa, continuando a história dessa pesquisa até o presente, como uma história aristotélica, agostiniana, tomista, humiana, liberal pós-iluminista ou qualquer outra.

Conseqüentemente, para cada um de nós, a questão agora é: a que questões, no debate contemporâneo, nos remete essa história particular? Que recursos nossa tradição particular nos oferece nessa situação? Podemos, através desses recursos, compreender as realizações e os sucessos, os fracassos e esterilidades de tradições rivais mais adequadamente do que seus próprios adeptos? Mais adequadamente, também segundo os deles? É à medida que as histórias narradas neste livro nos remetem a respostas a essas questões que elas podem também sustentar a promessa de responder às seguintes questões: justiça, de quem? Qual racionalidade? ${ }^{13}$

\section{Charles Taylor}

Segundo Taylor, as identidades humanas possuem um aspecto pessoal e um aspecto social. No primeiro caso, elas se formam a partir, tanto do descobrimento de cada um sobre si e sobre suas opiniões, como também do resultado de sua interação com os demais - a qual permanece dentro de cada um porque feita através da linguagem. É a exigência pela identidade pessoal de um reconhecimento oriundo das práticas lingüísticas.

A identidade social, por outro lado, requer um reconhecimento contínuo e igualitário, capaz de, ao mesmo tempo, assegurar a proteção contra o arbítrio e a 
manutenção das diferenças. É a falta de reconhecimento que gera, por exemplo, a opressão às mulheres e minorias raciais. O princípio da igualdade universal exige o reconhecimento das diferenças. Segundo CITTADINO:

Tanto quanto as identidades pessoais demandam um reconhecimento obtido pela via de um diálogo, as identidades sociais dependem de uma "política ininterrupta de reconhecimento igualitário". O reconhecimento igualitário das identidades sociais é, segundo Taylor, uma exigência contra a opressão, na medida em que a sua recusa conforma identidades sociais que internalizam signos de inferioridade e humilhação. Ao mesmo tempo, é o reconhecimento igualitário que assegura o espaço da diferença. Mais do que isso, é o princípio da igualdade universal que obriga ao reconhecimento das diferenças. ${ }^{14}$

Taylor busca realizar uma compreensão renovada da modernidade ou um entendimento mais produtivo e menos unilateral dos fenômenos da modernidade. Para tanto, discorre sobre a relação entre identidade e moralidade, inicialmente, para depois fazer um registro histórico da modernidade.

\section{A ligação entre individualidade e bem, ou seja, entre identidade e moralidade.}

A filosofia moral contemporânea tem tratado da moralidade de forma defeituosa, truncada e estreita, enfatizando mais a definição do conteúdo da obrigação, o "que é certo fazer;' do que a natureza do bom viver, o "que é bom ser", no bem como objeto do amor ou lealdade humanos. Diante dessa realidade, Taylor propõe a ampliação do campo tradicional das descrições morais legítimas e faz o exame das principais linguagens subjacentes que formam a base e o sentido das obrigações morais reconhecidas.

O autor faz a apresentação do pano de fundo da natureza humana e de suas situações espirituais, em que se alicerçam várias instituições morais e espirituais de hoje. Essa dimensão é extremamente importante e deve ser resgatada tendo em vista ser ignorada pela filosofia contemporânea. Para tanto, parte da análise de uma concepção mais ampla da moral, englobando não só os tradicionais conceitos de

\footnotetext{
${ }^{13}$ MACINTYRE, p. 430.

14 CITTADINO, Gisele. Pluralismo, Direito e Justiça Distributiva. Elementos da Filosofia Constitucional Contemporânea. Rio de Janeiro: Editora Lúmen Juris, 2004. p. 121.
} 
respeito à vida, bem-estar, justiça, dignidade das outras pessoas (tradicionalmente denominadas exigências morais), mas também temas ligados ao respeito próprio (daí o termo "espiritual), como o sentido da própria dignidade e questões sobre o que torna a vida significativa ou satisfatória. ${ }^{15}$

Em relação aos primeiros conceitos, que geram reações morais, há duas facetas:

De um lado, são quase como instintos, comparáveis a nosso amor por doces, nossa aversão a substâncias nauseantes ou nosso medo de cair; do outro, parecem envolver afirmações implícitas ou explícitas sobre a natureza e condição dos seres humanos. Nesta segunda perspectiva, uma reação moral configura-se como uma aceitação, uma afirmação, de dada ontologia do humano.

Uma importante corrente da consciência naturalista moderna tentou afastar essa segunda perspectiva e declará-la dispensável ou irrelevante para a moralidade. São múltiplos os motivos: em parte, isso resulta da desconfiança diante de todas as explicações ontológicas devido ao uso que foi dado a algumas delas, por exemplo justificar restrições ou exclusões de hereges ou de seres supostamente inferiores. E essa desconfiança é fortalecida quando reina um sentido primitivista de que a natureza humana imaculada respeita a vida por instinto. Mas também deve-se em parte à grande nuvem epistemológica sob a qual todas essas explicações se encontram para aqueles que seguiram teorias empiristas ou racionalistas do conhecimento, inspiradas pelo sucesso da ciência natural moderna. ${ }^{16}$

Mas o autor não abre mão desses dois lados das reações morais. Elas não são unicamente sentimentos viscerais, mas também reconhecimentos de enunciados relacionados ao objeto de tal reação moral. Toda argumentação e exploração moral só existe onde há resposta moral, com descrição do objeto dessa resposta (descrição intrínseca) cujos critérios são independentes de nossas reações de fato. O autor propõe a necessidade de "tratar nossos mais profundos instintos morais, nosso senso inerradicável de que a vida humana deve ser respeitada, como nossa forma de acesso ao mundo em que as afirmações ontológicas são discerníveis e podem ser discutidas e analisadas racionalmente."17

15 O pensamento moral apresenta três eixos: 1) o sentido de respeito pelos outros e de obrigação perante eles; 2) modos de compreender o que constitui uma vida plena; 3) noção de dignidade, no sentido de merecer respeito.

16 TAYLOR, Charles. As fontes do self. A construção da identidade moderna. São Paulo: Edições Loyola, 1997. p. 18.

17 TAYLOR, p. 23. 
Nesse aspecto, há a noção de respeito a direitos, no sentido de respeito ativo, de não-violação, de saber porque se deve respeitar os direitos alheios.

Em relação aos segundos conceitos, estão relacionados às interrogações em torno do sentido da vida, que ocorrem em qualquer cultura - onde sempre há alguma configuração (encontrada ou a ser buscada) que auxilia a definir as exigências que the são feitas e que vão medir a plenitude ou nulidade da sua vida. $\mathrm{Na}$ sociedade guerreira, por exemplo, o membro realiza façanhas corajosas para buscar a "fama na memória e no cântico da tribo" (a configuração).

(...) Não ter uma configuração é cair numa vida espiritualmente sem sentido. Logo, a busca é sempre uma busca de sentido.

Mas a invocação do sentido também decorre de nossa consciência de quanto a busca envolve articulação. Descobrimos o sentido da vida articulando-a. E os modernos adquiriram a consciência aguda de que o grau de sentido que existe para nós depende de nossos próprios poderes de expressão. Aqui, descobrir depende de inventar, e ambos se entrelaçam. Encontrar um sentido para a vida depende de construir expressões significativas adequadas. Há, portanto, algo particularmente apropriado à nossa condição da polissemia da palavra "sentido": vidas podem tê-lo ou carecer dele quando têm ou carecem de um objetivo; ao mesmo tempo em que a palavra também se aplica à língua e a outras formas de expressão. Nós, modernos, alcançamos cada vez mais o sentido na primeira acepção, quando o conseguimos, mediante sua criação na segunda. ${ }^{18}$

A configuração incorpora um conjunto de distinções qualitativas, no sentido de que pensar, sentir, agir no âmbito dessa configuração significa sentir que seu modo de vida ou de agir é superior, ou diferente, de outros que estão ao alcance (pela ética da honra, a vida do guerreiro é considerada superior à vida privada). $\mathrm{O}$ naturalismo e o utilitarismo rejeitavam a noção de distinção qualitativa, concebendo em pé de igualdade todos os objetivos humanos, passíveis, portanto, de quantificação e cálculo comuns, conforme uma referência única. O autor discorda radicalmente dessa noção a partir da idéia de "afirmação da vida cotidiana", a vida de produção e reprodução, de trabalho e da família é o principal locus do bem viver.

(...) A noção de que há certa dignidade e valor nesta vida requer um contraste; mas não mais, evidentemente, entre esta vida e alguma atividade "superior" como a contemplação, a guerra, a cidadania ativa ou o ascetismo heróico, mas entre diferentes maneiras de viver a

${ }^{18}$ TAYLOR, p. 33 
vida de produção e reprodução. A noção nunca é de que qualquer coisa que fazemos é aceitável. Isto seria ininteligível como base de uma noção de dignidade. O ponto essencial, é em vez disso, que o superior deve ser encontrado não fora da vida, mas como uma maneira de viver a vida cotidiana. ${ }^{19}$

\section{II - História e análise da identidade moderna}

A proposta de Taylor é resgatar a história da identidade moderna, desde sua gênese, estabelecendo o conjunto de compreensões do que é ser um agente humano, uma pessoa ou um self.

Três facetas dessa identidade são estabelecidas pelo autor:

1) Interioridade moderna: noção de que seres humanos são um self, dotados de profundezas interiores. Para tanto, é feita a análise desde Santo Agostinho, Descartes, Montaigne até hoje.

2) Afirmação da vida cotidiana que se desenvolve a partir do começo do período moderno, estudada desde a Reforma até o lluminismo e suas vertentes contemporâneas;

3) A natureza, em sua noção expressivista, como fonte moral interior, analisada a partir do final do século XVIII, em suas origens, até século XX, com suas manifestações na literatura, passando pelas transformações ocorridas no século XIX.

Com essa subdivisão, Taylor faz um verdadeiro resgate da história da modernidade com o objetivo de demonstrar sua influência.

“(...) só com uma perspectiva em profundidade da história conseguimos mostrar o que está implícito, mas ainda em atividade, na vida contemporânea: os temas românticos ainda vividos no modernismo, disfarçados às vezes pela postura anti-romântica dos modernistas; ou a importância crucial da afirmação da vida cotidiana que, em alguns aspectos, é tão entranhada que nem a percebemos; ou as raízes espirituais do naturalismo, que o modernismo em geral se sente forçado a suprimir."20

\footnotetext{
19 TAYLOR, p. 39 e 40.

20 TAYLOR, p. 636.
} 
A compreensão da identidade moderna auxilia 0 processo de autocompreensão e também o levantamento das três atuais áreas de tensão na cultura moral moderna:

1) a incerteza e divisão quanto aos bens constitutivos, ainda que haja concordância sobre os padrões morais. (fontes morais)

Os imperativos morais da cultura moderna surgem das noções dos padrões morais comuns de liberdade, benevolência, afirmação da vida cotidiana, justiça universal, igualdade, autogoverno, afastamento do sofrimento e da morte. Ocorre, porém, que as fontes morais, ou os bens constitutivos que determinam tais padrões são distintos. ${ }^{21}$. Assim, Taylor identifica três domínios das fontes morais, que podem comunicar-se:

4) a base teísta, unificada, que está na origem desses padrões;

5) o naturalismo da razão desprendida, que atualmente possui formas científicas e que baseia a ética austera da liberdade auto-responsável, da ética corajosa da crença, da benevolência;

6) o expressionismo romântico e visões modernistas posteriores, que dão relevo à capacidade de imaginação criativa, buscando também a dimensão interior da natureza.

Tais fontes e o seu produto, ou seja, a própria perspectiva moral moderna, têm conexões fortes com as diferentes concepções do self e suas características, as quais estão intrinsecamente ligadas a noções de interioridade - que por sua vez, é moderna e com perspectiva moral. Análises modernas não conseguem se dissociar de tais fontes.

Assim, os objetivos da revolução dos estudantes em Paris, em 1968, tinham aspirações românticas (de harmonia pessoal e interpessoal, de destruição de barreiras, etc), próximas a Schiller, numa perspectiva pré-schopenhaueriana, ainda que travestidas das formas modernistas do situacionismo, dadaísmo, surrealismos, etc. Do mesmo modo, os movimentos do "potencial humano" nos EUA tinham base no expressivismo original.

21 Taylor fala de "bem" enquanto "o que quer que seja selecionado como incomparavelmente superior numa distinção qualitativa. Pode ser uma ação, motivação ou estilo de vida julgado como sendo qualitativamente superior. "Bem" é usado aqui num sentido bastante geral, designando qualquer coisa considerada valiosa, digna, admirável, de qualquer tipo ou categoria". TAYLOR, p. 127. 
A divisão das fontes é motivo para o surgimento de um tipo de teoria moral em que se busca reconstruir a ética sem qualquer referência ao bem, como ocorre com a (meta) ética procedimentalista moderna. Esta vê os compromissos de benevolência e justiça pelo prisma da obrigação moral, tornando sua face negativa mais dominante e evidente e afastando-se das fontes morais.

Taylor tende para a perspectiva demonstrada por Dostoievski, de que o potencial de certa perspectiva teísta é incomparavelmente superior ao do humanismo naturalista.

2) o conflito entre o instrumentalismo desprendido e o protesto romântico ou modernista contra ele.

O surgimento do modernismo alterou a visão das alternativas à razão desprendida, questionando se a vida realizada esteticamente também seria moral (Baudelaire, Schopenhauer, Nietzsche) ou se a epifania artística levaria às mesmas coisas exigidas pela moralidade (Pound, Lawrence) O expressivismo romântico via a realização expressiva exatamente como algo compatível com a moralidade, exaltando sempre a arte. Buscava-se, portanto, uma realização mais plena.

O instrumentalismo recebeu críticas de diversas correntes:

- $\quad$ Primeiro, do ponto de vista da razão desprendida e do expressivismo subjetivo. A tendência na sociedade moderna para o modo de vida instrumental desprendido foi acusada de esvaziar a vida de significado e de ameaçar a liberdade pública - instituições e autogoverno. Assim ocorreu com os pensamentos da sociedade moderna como jaula de ferro (Weber), modelo de ação instrumental da teoria capitalista (Marx), desencantamento (Weber, a partir de Schiller), divisão ou fragmentação em relação à natureza (Marx, Lukács, Adorno e Horkheimer, Marcuse), perda de ressonância no ambiente humano, quanto a coisas e vínculos (Tudo que é sólido se dissolve no ar, Marx, Marshall Berman), utilização de artigos ruins e descartáveis, com o paradigma do dispositivo (Albert Borgman), efemeridade dos objetos modernos (Hannah Arendt).

- Segundo, do ponto de vista do subjetivismo de alguns escritores, tratando do problema experiencial subordinado ao moral e político. 
- Terceiro, do ponto de vista de todo o processo moderno, rejeitando a ordem cósmica pública de significados.

Taylor entende que essas três análises são muito estreitas e superficiais porque negam certos bens que são válidos quando analisados pela história da identidade moderna. São bens presentes na vida moderna, ainda que negados. Assim, os próprios racionalistas desprendidos se utilizam de noções como realização, ao tratarem de seus dilemas pessoais. Da mesma maneira, os antimodernos lançam mão de noções de direitos, igualdade, liberdade autoresponsável, além da realização. Também se acredita que a linguagem filosófica ou crítica relativa é exata e destituída dos fatores pessoais, considerados mero subjetivismo, a partir de uma adoção da concepção procedimentalista de oralidade (Habermas e Hare). Para o autor, na verdade, a linguagem não consegue escapar da ressonância pessoal (ele utiliza-se das imagens de ressonância pessoal profunda como "epifania", "fontes morais, "desprendimento", fortalecimento"), explorando a condição humana, sua inserção na natureza e no coletivo, como locus de fontes morais. Rilke fala em "louvar" e "tornar interior"

O poder da razão desprendida e auto-responsável gerou a visão do sujeito com self descontextualizado e pontual, ao se interpretar a postura do desprendimento na ontologia do sujeito, este como atividade separável de tudo quanto é apenas dado no ser: uma alma desencarnada (Descartes), uma potência pontual de auto-remodelação (Locke), um ser racional puro (Kant). Isso foi considerado como visão errônea, rejeitando-se os ideais de razão e liberdade. (Merleau-Ponty, Heidegger). Na verdade, não é que seja uma análise equivocada vez que válida, apenas não é necessária como base para a liberdade e a razão auto-responsável. Diante dessa polarização, é importante retirar as pré-concepções e desenvolver antropologias de liberdade contextualizada.

3) o questionamento sobre a compatibilidade dos padrões morais com a realização plena, com a pergunta de Nietzsche, Derrida e Foucault: a moralidade não nos cobra um preço muito alto em termos de totalidade? As exigências da benevolência podem cobrar um preço elevado em termos de amor por si próprio e auto-realização, gerando autodestruição e até violência. Então surge a rebelião naturalista contra as exigências ascéticas da religião, a rejeição iluminista do cristianismo e das ideologias milenaristas que têm alguma semelhança com a 
religião (em virtude de ideais de perfeição humana lançados por ateus que também causaram horrores), pregando então um humanismo sóbrio, secular, científico e neutro (Foucault). Taylor, no entanto, discorda dessa solução:

A adoção de uma perspectiva secular despojada, sem qualquer dimensão religiosa ou esperança radical na história, não é uma forma de evitar o dilema, embora possa ser uma boa maneira de conviver com ele. Não o evita porque isso também envolve sua "mutilação". Envolve que sufoquemos em nós a resposta a algumas das aspirações espirituais mais profundas e poderosas que os seres humanos já conceberam. Esse também é um preço muito alto a pagar. ${ }^{22}$

Os ideais e interditos da identidade moderna moldam o pensamento filosófico, a epistemologia e a filosofia da linguagem. Mesmo doutrinas decorrentes da análise de determinados domínios em que o self não interfere, refletem os ideais que ajudaram a constituir a identidade.

O objetivo central de Taylor é mostrar como seu quadro de identidade moderna pode moldar nossa visão da condição moral de nosso tempo. A identidade é muito rica em fontes morais, apesar de seus detratores não o reconhecerem nem seus defensores demonstrarem-no. Mas ao final, vai além e deixa escapar sua opinião: Há um elemento fundamental de esperança. É uma esperança que vejo implícita no teísmo judeu-cristão (por mais terrível que sejam os antecedentes de seus adeptos na história), e em sua promessa central de uma afirmação divina do humano, mais total do que os seres humanos jamais poderiam obter sem ajuda. ${ }^{23}$

\section{Michael Walzer}

Michael Walzer integra o grupo dos comunitaristas ao defender que o processo histórico conforma as individualidades. As identidades humanas se constituem no interior da história, na relação do diálogo de um com o outro, exigindo, portanto, seu reconhecimento. Seguindo a linha de pensamento de Taylor, Michael Walzer afirma que o reconhecimento é universal, enquanto o reconhecido é particular.

\footnotetext{
22 TAYLOR, p. 662.

${ }^{23}$ TAYLOR p. 663.
} 
Walzer aborda o tema da tolerância, ou aquilo que ela possibilita - que é a coexistência pacífica - utilizando-se da explanação de regimes de tolerância, ou seja, descrevendo de forma histórica e contextualizada as diferentes formas que a tolerância assumiu na realidade, bem como os problemas que elas enfrentaram (com base na Europa, América do Norte e Oriente Médio, explica o autor).

São cinco os modelos de sociedade tolerantes na lista (não-exaustiva) de Walzer, que recebem a denominação de regimes e que apresentam o pressuposto comum de que os grupos (religiosos, étnicos, nacionais) simplesmente existem: 1) Impérios multinacionais, como Pérsia, Egito ptolemaico e Roma, onde havia várias sociedades autônomas ou semi-autônomas sob o domínio imperial que incorporava a diferença e facilitava a coexistência - tal como ocorreu na Alexandria, no sistema millet (significa comunidade religiosa) dos otomanos e na URSS; 2) Sociedade internacional, com regime próprio, ainda que fraco, mas sempre tolerante com quem atinge a condição de Estado e atua dentro dos limites soberanos - embora com possibilidades de intervenções; 3) Consociações, ou seja, estados bi ou trinacionais, tais como Bélgica, Suíça, Chipre, Líbano ou a natimorta Bósnia, onde os diferentes grupos têm de tolerar uns aos outros já que não são tolerados por um único poder transcendente; 4) Estados-nações, cuja denominação significa "apenas que um único grupo dominante organiza a vida da comunidade de modo que ela reflita sua própria história e cultura e, quando as coisas acontecem como se deseja, a história prossegue e a cultura é preservada, reconhecendo indivíduos e fortalecendo um língua." ${ }^{24}$; 5) Sociedades imigrantes, em que os membros dos diferentes grupos abandonaram sua terra natal chegando de modo desorganizado e misturado, em outra terra, cujo Estado dar-lhes-á tratamento neutro, tolerando a todos. Eles não têm autonomia, acesso ao poder do Estado, reconhecimento oficial e base territorial.

O autor alerta para quatro casos que não se adéquam aos regimes anteriormente citados, por suas características peculiares: França, Israel, Canadá e Comunidade Européia. Além disso, enumera cinco problemáticas enfrentadas pelos regimes na prática: 1) Poder, já que a tolerância pode ser um ato de poder em que ser tolerado é a aceitação da própria fraqueza em relação ao tolerante; 2) Classe, tendo em vista que a intolerância é maior quando as minorias (culturais, étnicas, raciais) também são de classe econômica inferior; 3) Gênero, porque questões

${ }^{24}$ WALZER, Michael. Da Tolerância. São Paulo: Martins Fontes, 1999. p. 34. 
envolvendo papel dos sexos, organização familiar e comportamento sexual geram discordâncias há muito tempo, principalmente em função do tema do relativismo cultural; 4) Religião, tendo em vista que as religiões toleradas fazem a restrição individual, por conceito; 5) Educação, com papel fundamental na reprodução do próprio regime de tolerância; 6) Religião Civil, enquanto credo do próprio Estado, doutrina que imprime aos cidadãos e que é crucial para sua reprodução e estabilidade, podendo tolerar outras religiões civis no contexto da sociedade internacional mas nunca dentro de seu regime; 7) A questão da tolerância com os intolerantes, vista como o problema central e mais difícil na teoria da tolerância e que, na prática dos regimes, não ocorre.

Entende Walzer que, quando os grupos dentro da sociedade se preservam a si mesmos, a resignação, a indiferença ou a aceitação estóica são suficientes para sua coexistência. Além disso, a tolerância funciona bem com qualquer uma das atitudes do continnuum de resignação, indiferença, estoicismo, curiosidade e entusiasmo

Walzer aponta dois projetos modernistas: o primeiro, da inclusividade democrática de indivíduos singulares (judeus, trabalhadores, mulheres, negros e imigrantes); segundo, o da separação dos grupos que vão se formando por tais indivíduos, dando-lhes um espaço e política próprios em função de sua mobilização e da ação de seus líderes. "Agora o que se exige não é uma luta pela inclusão, mas uma luta por fronteiras. A principal palavra de ordem dessa luta é "autodeterminação", que implica a necessidade de um pedaço de território ou pelo menos de um conjunto de instituições independentes - daí a descentralização, a devolução, a autonomia, a divisão ou a soberania." ${ }^{25}$

Existem aqueles que preferem participar de tais grupos e outros que preferem fugir de tais limites. Não há juízo de valor nessa dicotomia e a "tensão precisa ser solucionada caso a caso" de acordo com as peculiaridades de cada grupo, afinal "que orgulho sentiriam numa evasão em que nunca se lhes opôs resistência? E quem seriam eles se não tivessem de lutar para ser o que são? A coexistência de grupos fortes e indivíduos livres, com todas as suas dificuldades, é uma característica permanente da modernidade. ${ }^{26}$

\footnotetext{
${ }^{25}$ WALZER, p. 112.

${ }^{26}$ MACINTYRE, p. 114.
} 
Mas o autor vai além e percebe um modelo mais novo de tolerância: nas sociedades e Estados com imigrantes o multiculturalismo é muito intenso, tendo em vista que as pessoas passam a viver sem identidades e fronteiras definidas, com diversidade dispersa devido à mistura de indivíduos e com menor controle do grupo por seus membros. A relação entre as pessoas são frouxas, baseadas em fragmentos de culturas e religiões passadas e a idéia de "preferências ou aversões pessoais" podem substituir a de tolerância e intolerância e "alianças temporárias" podem estar no lugar dos grupos. Trata-se do projeto pós-moderno que "solapa qualquer espécie de identidade comum e comportamento padrão", em que se destaca Julia Kristeva, escritora búlgara-francesa que propõe o reconhecimento da condição de estrangeiro em nós mesmos, já que ela é universal. ${ }^{27}$

Ocorre, porém, que o projeto moderno continua coexistindo com o pósmoderno. Então há que haver a valorização não só da liberdade pessoal, mas também da adesão a grupos, ainda que eles estejam enfraquecidos e precisem de ajuda.

Indivíduos livres e isolados em sociedade democráticas não oferecerão essa ajuda nem autorizarão seus governos a fazê-lo, a menos que reconheçam a importância dos grupos (do seu e de todos os outros) na formação de indivíduos como eles mesmos - a menos que reconheçam que o objetivo da tolerância não é, e nunca foi, o de abolir o "nós" e o "eles" (e com certeza não é o de abolir o "eu"), mas o de garantir a continuidade de sua coexistência e interação pacíficas. As identidades divididas da pós-modernidade complicam a coexistência, mas também dependem dela para a sua própria criação e autoentendimento. ${ }^{28}$

\section{COMUNITARISMO NO BRASIL?}

Autores brasileiros praticamente não são incluídos no rol dos pensadores adeptos da filosofia comunitarista. Cittadino, no entanto, identifica influência dessa linha de pensamento na Constituição brasileira, a partir do trabalho de estudiosos constitucionalistas.

Com efeito, uma parcela significativa dos constitucionalistas brasileiros - contrária à cultura jurídica positivista e privatista prevalecente e influenciada pelos trabalhos de vários

\footnotetext{
${ }^{27}$ WALZER, p. 116.

${ }^{28}$ WALZER, P. 120.
} 
representantes do constitucionalismo português e espanhol contemporâneo - participou ativamente do processo constituinte brasileiro nos anos 80 , procurando contribuir com a elaboração de uma Constituição adequada à conformação de uma sociedade justa no País. (...) esses constitucionalistas não pretenderam apenas participar do processo de reconstrução do Estado de Direito após anos de autoritarismo militar, mas fundamentalmente procuraram, contra o positivismo e revelando o seu compromisso com os ideais do pensamento comunitário, dar um fundamento ético à nova ordem constitucional brasileira, tomando-a como uma estrutura normativa que incorpora os valores de uma comunidade histórica concreta. Neste processo, é tão significativa a influência do pensamento comunitário nos trabalhos desses autores - ainda que a adoção das concepções e compromissos comunitários derive do constitucionalismo ibérico - que nos pareceu razoável designá-los como representantes do "constitucionalismo comunitário brasileiro". Ressalte-se, de outra parte, que este "constitucionalismo comunitário", em face da atuação decisiva de seus representantes ao longo do processo constituinte, registrou a sua marca em nosso ordenamento constitucional. Na verdade, é possível identificar na Constituição Federal não apenas uma linguagem comunitária, mas um compromisso com o ideário comunitário.

Ao adotar o ideário comunitário e lutar por sua inclusão no ordenamento constitucional do País, os "constitucionalistas comunitários" brasileiros se envolvem no debate acerca de como é possível conformar uma sociedade justa e uma estrutura normativa a ela adequada. No entanto, como referimos, esta discussão tem seu início no âmbito da filosofia política contemporânea e organiza-se em torno dos debates sobre relações entre ética, direito e política. ${ }^{29}$

Pelo aspecto comunitarista, a Constituição atua como depositária dos valores de uma sociedade, enfatizando sua realidade social e cultural. Ela enfatiza os direitos fundamentais sem limitar-se à concepção individualista, defende a autonomia privada, desde que delimitada pela soberania popular, incentiva a democracia participativa e a prestação positiva do Estado.

\section{A CRÍTICA DE DUSSEL}

Dussel reconhece a existência e o trabalho dos comunitaristas e enquadraos dentro do momento material da ética. Critica-os, no entanto, em virtude da

${ }^{29}$ CITTADINO, Gisele. Pluralismo, Direito e Justiça Distributiva. Elementos da Filosofia Constitucional Contemporânea. Rio de Janeiro: Editora Lúmen Juris, 2004. p. 3 e 4. 
adoção de um princípio ético não-universal, centrado em valores e contextos que não abrangem a totalidade da realidade mundial.

Os comunitaristas ocupam então um lugar próprio no panorama contemporâneo norteamericano das éticas de conteúdo, que a filosofia latino-americana, a africana ou a asiática podem estudar com simpatia - dada a necessidade de indicar a legítima hegemonia do ethos eurocêntrico com pretensão de universalidade - mas que, ao mesmo tempo, devem ser superadas a partir de um princípio material universal, e a partir de um diálogo intercultural não eurocentricamente redefinido. ${ }^{30}$

O autor também não se conforma com a visão restrita que se faz de cada comunidade, de forma isolada, e sem diálogos entre elas. Então critica, finalizando: Ao recuperar a historia da eticidade, alguns comunitaristas não deixam por isso de cair em certos extremos opostos: o de afirmar a incomensurabilidade de cada "mundo de vida"; o de ignorar um princípio material universal, o de não estar atentos ao momento material ao qual os utilitaristas haviam feito referência. ${ }^{31}$

\section{BIBLIOGRAFIA}

CITTADINO, Gisele. Pluralismo, Direito e Justiça Distributiva. Elementos da Filosofia Constitucional Contemporânea. Rio de Janeiro: Editora Lúmen Juris, 2004.

DUSSEL, Enrique. Ética da Libertação na idade da globalização e exclusão. Petrópolis, Editora Vozes, 2000.

MACINTYRE, Alasdair. Justiça de quem? Qual racionalidade? 2 ed. São Paulo: Loyola, 2001.

TAYLOR, Charles. As fontes do self. A construção da identidade moderna. São Paulo: Edições Loyola, 1997.

WALZER, Michael. Da Tolerância. São Paulo: Martins Fontes, 1999.

\footnotetext{
${ }^{30}$ DUSSEL, p. 117.

${ }^{31}$ DUSSEL, p. 116.
} 